\title{
SURGERY OF TETRALOGY OF FALLOT-15 YEAR EXPERIENCE AT AFIC-NIHD RAWALPINDI
}

\author{
Syed Shahid Nafees Zaidi, Inamullah Khan, Nausheen Bakht*, Syeda Aliza Shahid**, Khurram Akhtar, Hajira Akbar, \\ Amjad Mahmood, Intisar Ul Haq, Nadeem Sadiq, Dawood Kamal, Hafsa Khalil
}

\begin{abstract}
Armed Forces Institute of Cardiology/National Institute of Heart Disease (AFIC/NIHD)/National University of Medical Sciences (NUMS) Rawalpindi Pakistan, *Armed Forces Post Graduate Medical Institute/National University of Medical Sciences (NUMS) Rawalpindi Pakistan, ${ }^{* *} \mathrm{CMH}$ Lahore Medical College, Lahore/National University of Medical Sciences (NUMS) Pakistan
\end{abstract}

\begin{abstract}
Objective: To compare trans-atrial/Trans-pulmonary and trans-annular/trans-ventricular techniques of surgical correction of tetralogy of fallot.

Study Design: Descriptive cross sectional study.

Place and Duration of Study: AFIC-NIHD Rawalpindi, from Jan 2005 to Jan 2020.

Methodology: Pre-op variables included age, gender, weight, SaO2 and any previous operation (like Modified Blalock Taussig Shunt.) Operative variables were any previous Blalock Taussig Shunts and if present, then their takedown, Cardiopulmonary Bypass Time, Aortic Clamp Time, any Right Ventricle - Pulmonary Artery conduit, Main Pulmonary Artery patch-plasty, Left Pulmonary Artery/ Right Pulmonary Artery patch-plasty, dosage of inotropes and pacing started during weaning off CPB. Post-op variables were mechanical ventilation time (hrs), ventilation time $>72 \mathrm{hrs}$, dosage and duration of inotropes, pacing $>24 \mathrm{hrs}$, renal complications, neurological complications, sepsis, low cardiac output, re-ventilation, tachyarrythmias, any re-opening surgery, mean intensive care unit stay (hrs), overall hospital stay (days) and overall all-cause mortality.

Results: A total of 1271 TOF patients were operated. In (38.6\%) cases Trans-atrial / Trans-pulmonary approach was used while in $780(61.3 \%)$ correction was done by TAP/TV technique. In both techniques, male patients were $365(66.4 \%)$ vs. $73(64.1 \%)$ females. Mean age was $5 \pm 2.3$ vs. $4 \pm 2.5$ years, MPA patch-plasty was $190 \pm 5(38.6 \%)$ vs. $780 \pm 8(100 \%)(p-0.058)$, RPA/LPA Patch Plasty was $25 \pm 6(5 \%)$ vs. $180 \pm 10$ (23\%) (p- 0.025), In ICU, Ventilation hours was $25 \pm 8$ and $30 \pm 12$, Ventilation $>72$ Hrs was 15 (3\%) vs. 65 (8.3\%) ( $p$-0.015), Inotrope duration $>72$ Hours was $90(18.3 \%)$ vs. $400(51.2 \%)$ (p-0.338), pacing >24 hours was $30(6.1 \%)$ vs. $150(19.2 \%)(p-0.0001)$, renal complications were $10(2.3 \%)$ vs. $35(4.4 \%)$ (p- 0.285), Neurological complications were $7(1.4 \%)$ vs. $15(1.9 \%)(p-$ 0.553), Sepsis was $11(2.2 \%)$ vs. 47 (6\%) (p-0.33), Low cardiac output was 15 (3\%) vs. $66(8.4 \%)(p$ - 1.000), re-ventilation was $10(2 \%)$ vs. $110(14 \%)$ (p-0.41), Tachy-arrhythmia was $25(5 \%)$ vs. $150(19.2 \%)$ ( $p$ - 0.11), re-openings were $19(3.8 \%)$ vs. $65(8.3 \%)$ (p- 0.0003), ICU stay (Hours) was $87 \pm 8$ vs. $108 \pm 10$, Mortality was 35 (7.1\%) vs. 75 $(9.6 \%)(p-0.094)$, Mean hospital stay (Days) was $12.2 \pm 2.5$ vs. $15.8 \pm 4.9$.

Conclusion: Fifteen years' experience of Tetralogy of fallot corrections at AFIC-NIHD indicates that Trans-atrial / Trans-pulmonary approach is more beneficial to patients due to high survival rate, less morbidity, less hospital stay and an early discharge. This ultimately translates into less financial burden on the patients, hospital, society and the country at large.
\end{abstract}

Keywords: Tetralogy of fallot, Trans-atrial/trans-pulmonary repair, Trans-annular patch/trans-venrticular repair, Total correction of tetralogy of fallot.

\footnotetext{
This is an Open Access article distributed under the terms of the Creative Commons Attribution License (http://creativecommons.org/licenses/by/4.0), which permits unrestricted use, distribution, and reproduction in any medium, provided the original work is properly cited.
}

\section{INTRODUCTION}

Tetralogy of Fallot (TOF) is the commonest type of cyanotic congenital heart disease having an incidence of 3/1000 live births ${ }^{1}$. Its classical tetrad comprises of right ventricular outflow tract obstruction (RVOTO), ventricular septal defect

Correspondence: Dr Syed Shahid Nafees Zaidi, Peads Cardio Surgery, AFIC/NIHD Pakistan
(VSD), overriding aorta, and RV hypertrophy.

This anomaly was first mentioned in 1673 by Bishop \& Steno but it was extensively elaborated upon by Fallot in $1888^{2}$. The etiology of TOF is largely unknown but is said to be associated with environmental factors and genetic disorders and in one study chromosomal alterations were found in $30 \%$ patients 3 . 
The only definitive treatment for TOF is total surgical correction which has consistently impro-ed since the first surgical repair in 1954. Transatrial/trans-pulmonary (TA/TP) and transannular patch/trans-ventricular (TAP/TV) repair are two well-known surgical techniques for total correction of TOF. Improved treatment strategies have resulted in excellent long-term survival (30year survival ranges from $68.5 \%-90.5 \%)^{4}$.

The selection of techniques depends upon case presentation and anatomical defects. Both techniques have their pros and cons. Advantages of TA/TP approach include shorter cardiopulmonary bypass (CPB) and aortic clamp time (ACT), smoother separation from $\mathrm{CPB}$, minimal use of inotropes, lesser post-operative bleeding, lesser blood products transfusion, lesser reopening rate, smoother course in ICU, earlier extubation, minimal pleural drainage, minimal ICU and hospital stay, lesser mortality, an earlier hospital discharge ${ }^{5}$ and low rate of repeat sternotomy for right ventricular outflow tract (RVOT) reconstruction 6 .

TAP/TV correction is done to get the required RVOT dimension when the pulmonary valve is either hypoplastic/severely stenosed along with a ver tight infundibular stenosis. Although short term advantages of TAP/TV are fewer, but its long term prognosis and functional capacity is not shown to be significantly inferior to TA/TP approach7.

\section{METHODOLOGY}

Armed Forces Institute of CardiologyNational Institute of Heart Diseases (AFICNIHD) Rawalpindi, Pakistan, Cardiac Surgery database was analyzed from January 2005 to January 2020. Institutional Review Board of the hospital approved the study. Inclusion Criteria were operations done for TOF in the last 15 years. Exclusion Criteria included double outlet right ventricle (DORV) with aortic override $>80 \%$, and TOF with other associated anomalies like complete and partial anomalous pulmonary venous drainage (TAPVR/PAPVR), one and half ventricle repairs, pulmonary atresia (PA), atrio- ventricular septal defect (AVSD) and absent pulmonary valve syndrome (APVS). Pre-op variables included age, gender, weight, $\mathrm{SaO} 2$ in air and history of any previous operation like Modified Blalock Taussig Shunt (MBTS).

Operative variables were take-down of MBTS if present, cardiopulmonary bypass time $(\mathrm{CPB})$, aortic clamp time $(\mathrm{ACT})$, right ventricle pulmonary artery (RV-PA) conduit insertion, main pulmonary artery (MPA) patch-plasty, right pulmonary artery/left pulmonary artery (RPA/ LPA) patch-plasty, inotropes dosage given (low / moderate/high) and initiation of pacing during weaning off $\mathrm{CPB}$.

Post-op variables included mechanical ventilation time (hours), ventilation time $>72$ hours, inotropes dosage given (low/ moderate / high), duration of inotropes $>72$ hours, pacing continuation $>24$ hours, renal complications, neurological complications, sepsis, low cardiac output failure, re-ventilation, tachyarrythmias, any reopening surgery, mean ICU stay (hrs), overall hospital stay (days) and overall all-cause mortality.

\section{Surgical Technique}

All operations were done on standard cardiopulmonary bypass with aortic and bi-caval cannulation, moderate hypothermia of $32 \mathrm{C}$ and warm blood cardio-plegia. Topical cooling with slush/cold saline was used for better myocardial protection.

Both techniques needed relief of RVOTO and VSD closure. In TA/TP correction, RVOTO was relieved by resecting infundibular bands transatrially and pulmonary valvular stenosis was relieved by mechanical Hegar's dilatation \pm pulmonary valve commissurotmy.

The ultimate target was to achieve a pulmonary valve annulus of size $z \pm 1-3$ score. In $\mathrm{TAP} / \mathrm{TV}$ correction, severe RVOTO needed either a right ventriculotomy and/or pulmonary valve incision (sacrificing its leaflet) to achieve a pulmonary valve annulur size $\mathrm{z} \pm 1-3$ score. Pulmonary and ventricular patch was either 
bovine/autologous pericardium, depending upon surgeon's choice. In both techniques, VSD closure was done by Dacron patch stitched in place with interrupted pledgetted sutures.

\section{Statistical Analysis}

Data was analyzed using SPSS version 22. Mean and standard deviation (SD) was used for quantitative variables while frequencies and percentage were used for description of qualitative variables. Independent sample's t-test was used for comparison of quantitative variables. Chi-square test was used for comparison of qualitative variables between different groups. A two-tailed $p<0.05$ was considered statistically significant.

\section{RESULTS}

From 2005 to 2020 total 1271 TOF patients were operated. In 491 (38.6\%) cases TA/TP app-

\section{DISCUSSION}

Keeping the anatomy of the defect in view, $780(61.3 \%)$ of TOF corrections were operated via $\mathrm{TAP} / \mathrm{TV}$ technique while in 491 (38.6\%) TA/TP technique was done. However, other studies have shown a higher number of TA/TP techniques than TAP/TV technique ${ }^{8}$. Male patients were more in number in both techniques of corrections. A similar gender ratio has been exhibited in other studies as well9.

Internationally, the trend is doing neonatal correction of TOF and some surgeons have even recommended performing the same on circulatory arrest. Some have shown good results ${ }^{10}$, however in one meta-analysis on 8 studies having 3858 patients, $19 \%$ neonatal repairs resulted in increased mortality, longer ICU and hospital stays ${ }^{11}$. The minimum age of our patients was $\geq 1$

Table-I: Pre-op variables of TA/TP and TAP/TV repairs for TOF.

\begin{tabular}{|c|c|c|c|c|}
\hline \multicolumn{2}{|c|}{ Variables } & TA/TP $(n=491)$ & TAP/TV $(n=780)$ & $p$-value \\
\hline \multicolumn{2}{|c|}{ Age (years) } & $5 \pm 2.3$ & $4 \pm 2.5$ & \\
\hline \multirow{2}{*}{ Gender } & Male & $320(65.1 \%)$ & $520(66.6 \%)$ & \multirow[b]{2}{*}{0.036} \\
\hline & Female & $171(34.8 \%)$ & $260(33.3 \%)$ & \\
\hline \multicolumn{2}{|c|}{ Weight $(\mathrm{Kg})$} & $15 \pm 3.5$ & $13 \pm 4.5$ & \\
\hline \multicolumn{2}{|c|}{$\mathrm{SaO} 2$ (Mean) } & $82.3 \pm 1.3$ & $65.2 \pm 2.5$ & \\
\hline \multicolumn{2}{|l|}{ MBTS } & $15(3.05 \%)$ & $50(6.41 \%)$ & 0.024 \\
\hline \multicolumn{5}{|c|}{ Table-II: Comparison of operative variables of TA/TP and TAP/TV techniques. } \\
\hline \multicolumn{2}{|c|}{ Variable } & TA/ TP & TAP/TV & $p$-value \\
\hline \multicolumn{2}{|c|}{ MBTS take down } & $15(3.05 \%)$ & $50(6.41 \%)$ & 0.049 \\
\hline \multicolumn{2}{|c|}{ CPB time (Mean) } & $135 \pm 6$ Min & $165 \pm 8$ Min & \\
\hline \multicolumn{2}{|c|}{ ACT time (Mean) } & $90 \pm 5$ Min & $125 \pm 8$ Min & \\
\hline \multicolumn{2}{|c|}{ RV-PA conduit } & - & $14(1.79 \%)$ & 0.044 \\
\hline \multicolumn{2}{|c|}{ MPA patch-plasty } & $190 \pm 5(38.6 \%)$ & $780 \pm 8(100 \%)$ & 0.058 \\
\hline \multicolumn{2}{|c|}{ RPA/LPA patch-plasty } & $25 \pm 6(5 \%)$ & $180 \pm 10(23 \%)$ & 0.025 \\
\hline \multirow{3}{*}{ Inotrope } & Mild & $350(71.2 \%)$ & $250(31.6 \%)$ & \multirow{3}{*}{0.031} \\
\hline & Moderate & $100(20.3 \%)$ & $450(57.6 \%)$ & \\
\hline & High & $41(8.3 \%)$ & $80(10.2 \%)$ & \\
\hline \multicolumn{2}{|c|}{$\begin{array}{l}\text { Temporary pacing initiated } \\
\text { (before CPB weaning off) }\end{array}$} & $360 \pm 10(73.3 \%)$ & $760 \pm 15(97.4 \%)$ & \\
\hline
\end{tabular}

roach was used while in $780(61.3 \%)$ TAP/TV approach was employed. The details of pre-operative variables are shown in table-I. Results of the operative variables are depicted in table-II. Results of ICU variables are depicted in table-III. Incidental anatomical findings in patients undergoing TOF repairs are shown in table-IV. year, because our institute neither recommends neonates for TOF surgery nor circulatory arrest during operation. Others suggest an optimum age of 3-11 months for TOF correction ${ }^{12}$.

Parameters used by surgeons' while selecting the operative techniques include pre-operative $\mathrm{SaO} 2,2 \mathrm{D}$-Echocardiography findings (like 
hypoplastic pulmonary annulus) and Cine angiography.

All MBTS were taken down during total corrections. This is quite a complex undertaking since it is done before establishing cardio-pulmo- save LAD in all these cases, right ventricle to pulmonary artery (RV-PA) conduit (Contegra, Medtronic) of $16-20 \mathrm{~mm}$ size was implanted, while in TA/TP cases it was not needed $(p=0.044)$. Others report similarly ${ }^{15}$.

Table-III: Comparison of ICU \& post-op variables of TA/TP and TAP/TV TOF repairs.

\begin{tabular}{l|c|c|c}
\hline Variable & TA/TP & TAP/TV & $p$-value \\
\hline Ventilation (Hrs) & $25 \pm 8$ & $30 \pm 12$ & 0.015 \\
\hline Ventilation $>72$ Hrs & $15(3 \%)$ & $65(8.3 \%)$ & 0.031 \\
\hline Inotropes dosage Mild & $401(81.6 \%)$ & $400(51.2 \%)$ & \\
\hline Moderate & $70(14.2 \%)$ & $300(38.4 \%)$ & 0.338 \\
\hline High & $20(4 \%)$ & $80(10.2 \%)$ & 0.0001 \\
\hline Inotrope duration $>72$ Hrs & $90(18.3 \%)$ & $400(51.2 \%)$ & 0.285 \\
\hline Pacing >24 hours & $30(6.1 \%)$ & $150(19.2 \%)$ & 0.553 \\
\hline Renal complications & $10(2.3 \%)$ & $35(4.4 \%)$ & 0.33 \\
\hline Neurological complications & $7(1.4 \%)$ & $15(1.9 \%)$ & 1.000 \\
\hline Sepsis & $11(2.2 \%)$ & $47(6 \%)$ & 0.41 \\
\hline Low cardiac output & $15(3 \%)$ & $66(8.4 \%)$ & 0.11 \\
\hline Re-ventilation & $10(2 \%)$ & $110(14 \%)$ & 0.0003 \\
\hline Tachy-arrhythmia & $25(5 \%)$ & $150(19.2 \%)$ & 0.094 \\
\hline Re-openings & $19(3.8 \%)$ & $65(8.3 \%)$ & \\
\hline ICU stay (Hours) & $87 \pm 8$ & $108 \pm 10$ & $75(9.6 \%)$ \\
\hline Mortality & $35(7.1 \%)$ & $15.8 \pm 4.9$ & \\
\hline Mean hospital stay (Days) & $12.2 \pm 2.5$ & & \\
\hline
\end{tabular}

nary bypass and complications can happen during its take down. We also lost 2 patients due to tearing of lobar arteries and lung haemorrhage.

Presently MBTS has largely been surpassed by pulmonary artery ballooning and/or RVOT/ PDA stenting which is life saving for babies presenting with cyanotic spells, having a small McGoon Index and an unsuitable anatomy for total correction like very small size branch pulmonary arteries for an MBTS. Additionally, it also provides time for pulmonary vasculature to grow by increasing pulmonary blood ${ }^{13}$.

$\mathrm{CPB}$ time was 30 minutes lesser in TA/TP than TAP/TV. The difference was however not statistically significant. ACT was 35 minutes lesser in TA/TP as compared to TAP/TV, This was not statistically significant. Longer $\mathrm{CPB}$ and $\mathrm{ACT}$ cause more likelihood of junctional ectopic tachycardia (JET) which in turn increases mortality ${ }^{14}$.

Left anterior descending artery (LAD) crossed RVOT in $14(1.79 \%)$ of TAP/TV cases and to
Main pulmonary artery (MPA), right pulmonary artery/left pulmonary artery (RPA/LPA), patch plasty was done either by bovine or auto-

Table-IV: Incidental anatomical findings in patients undergoing TOF repairs.

\begin{tabular}{l|c|c}
\hline Incidental anatomical findings & $\mathbf{n = 2 0 5}$ & $\mathbf{0}$ \\
\hline Atrial septal defect & 70 & 5.5 \\
\hline Patent ductus arteriosus & 50 & 3.9 \\
\hline Left superior vena cava & 25 & 1.9 \\
\hline$>$ 1 ventricular septal defects & 8 & 0.62 \\
\hline Sub-aortic membrane & 7 & 0.55 \\
\hline Right aortic arch & 45 & 3.5 \\
\hline
\end{tabular}

logous pericardium. Branch pulmonary artery patch plasty was also done where MBTS had been taken down to address the stenosis at the shunt insertion site.

During weaning off $\mathrm{CPB}, \mathrm{TA} / \mathrm{TP}$ cases require smaller doses of inotropes while TAP/TV patients needed higher doses $(p=0.031)$. Others have reported similarly ${ }^{16}$. 
During ICU stay, ventilation time $>72$ hours was observed to be $15(3 \%)$ in TA/TP vs. 65 $(8.3 \%)$ in TAP/TV cases $(p=0.015)$. This increased ventilation time in TAP/TV cases is also reported by other studies ${ }^{17}$.

Re-opening for hemorrhage was 19 (3.8\%) in TA/TP vs. $65(8.3 \%)$ in TAP/TV $(p=0.0003) .418$ and $522 \mathrm{ml}$ of blood products were transfused in TA/TP and TAP/TV respectively. On an average, more blood products were transfused in both techniques as compared to other studies ${ }^{18}$.

Mean pleural drainage was $180 \mathrm{ml}$ in TA/TP vs. $580 \mathrm{ml}$ in TAP/TV and the drainage duration was $2 \pm 1$ and $5 \pm 3$ days respectively. This increased amount of pleural effusion in TAP/TV. Other studies report similar results ${ }^{19}$. Mean ICU stay was 87.8 hours in TA/TP vs. 93.3 hours in TAP/ TV. This ICU stay time was more in our study as compared to other studies ${ }^{20}$.

An all-cause hospital mortality of 35 (7.1\%) of TA/TP vs. 75 (9.6\%) for TAP/TV patients, $(p=0.094)$. Our mortality of TA/TP and in TAP/ TV cases are more as compared to international studies $^{21}$. The dismal situation is likely to improve by having a dedicated ECMO program, keeping nurse-bed ratio as per international recommendations and making services of a resident intensivist available.

An important cause of mortality is bypass time (BPT) and aortic clamp time (ACT). BPT and ACT were not statistically different in both techniques. Studies have shown that these longer durations lead to increase mortality ${ }^{22}$.

Arrythmia was another cause of mortality like SVT, Nodal and JET. JET is an important complication during the postoperative period as it increases ventilation time, inotropic support, and length of ICU and hospital stay. Its risk factors are younger age, longer aortic crossclamping/bypass times, calcium and magnesium deficiency. JET has been observed as a cause of mortality in other studies too ${ }^{23}$. Another study showed a $12 \%$ incidence of arrhythmia in TOF patients leading to an approximate mortality between $11 \%-13 \%{ }^{24}$.
Mortality in TAP/TV cases is also attributable to a post repair higher grade of pulmonary insufficiency. One of the techniques to reduce this risk of pulmonary insufficiency is to apply on RVOT, a monocusp patch of either PTFE membrane or autologous pericardium. It has shown good results in some studies. It was applied in 25 $(21.9 \%)$ of our cases with acceptable results. In our study, TAP/TV TOF repair had a higher mortality than TP/TV repair but it was not statistically significant.

One study which compared 46 years of data showed that TAP/TV repair did cause late RV dysfunction but it did not led to mortality ${ }^{24}$ Good long term outcome of TP/TV is also supported by other studies 25 . The average hospital stay in $\mathrm{TA} / \mathrm{TP}$ repair was 7 days vs. 10 days in TAP/TV repair.

To summarize, TA/TP corrections of TOF fare better than TAP/TV repair in terms of inotropes use, pacing requirement, ventilation hours, post-operative hemorrhage re-opening, ICU stay and total hospital stay. In our study, mortality with both techniques was not statistically different.

\section{CONCLUSION}

Fifteen years of TOF corrections at AFICNIHD reveal that TA/TP approach is beneficial for patients on account of fewer complications, shorter mean ICU stay and earlier hospital discharge. With this technique, the various advantages are: Lesser requirement of previous MBTS, Lesser number of taken down in definitive correction, Lesser requirement of RV-PA conduit placement, Lesser pacing requirement, Lesser amount of inotropes given, Fewer cases need ventilation $>72$ hours in ICU, Lesser re-opening for post-op bleeding, Lesser all-cause mortality. This ultimately translates into less financial burden on the patient, hospital, society and the country at large.

\section{CONFLICT OF INTEREST}

This study has no conflict of interest to be declared by any author. 


\section{REFERENCES}

1. van der Linde $D$, Konings EE, Slager MA, Witsenburg M, Helbing WA, Takkenberg JJM, et al. Birth prevalence of congenital heart disease worldwide: A systematic review and metaanalysis. J Am Coll Cardiol 2011; 58(21): 2241-47.

2. Neill CA, Clark EB. Tetralogy of Fallot. The first 300 years. Tex Heart Inst J 1994; 21(4): 272-79.

3. Peng R, Zheng J, Xie HN. Genetic anomalies in fetuses with tetralogy of Fallot by using high-definition chromosomal microarray analysis. BMC Published online 2019; 17(1): 1-8.

4. Jelle PG, den Bosch EV, Bogers AC, Helbing AW. Current outcomes and treatment of tetralogy of Fallot. Res 2019; 8(): 1530-44.

5. d'Udekem Y, Galati JC, Rolley GJ, Konstantinov IE, Weintraub RG, Grigg L. et al. Risk of pulmonary valve implantation after a policy of transatrial repair of tetralogy of Fallot delayed beyond the neonatal period: the Melbourne experience over 25 years. J Am Coll Cardiol 2014; 63(6): 563-68.

6. Sun G, Wang X, Chen J, Ma R, Li F, Chen L, et al. Primary repair of tetralogy of Fallot in infants: Transatrial/transpulmonary or transventricular approach. Asian J Surg 2013; 36(4): 137-43.

7. Kim H, Sung SC, Kim SH, Chang YH, Lee HD, Park JA.et al. Early and late outcomes of total repair of tetralogy of Fallot: risk factors for late right ventricular dilatation. Interact Cardiovasc Thorac Surg 2013; 17(6): 956-62.

8. Luijten LWG, van den Bosch E, Duppen N, Roos-Hesselink RTJ, Nijveld A, Dijk A, et al. Long-term outcomes of transatrial-transpulmonary repair of tetralogy of Fallot. Euro J Thorac Surg 2015; 47(3): 527-34.

9. Spiewak M, Małek LA, Petryka LJ, Mazurkiewicz L, Werys K, Elzbieta K, et al. Repaired tetralogy of Fallot: ratio of right ventricular volume to left ventricular volume as a marker of right ventricular dilatation. Radiology 2012; 265(1): 78-86.

10. Van Arsdell GS, Maharaj GS, Tom J, Rao VK, Coles JG, Freedom $\mathrm{RM}$, et al. What is the optimal age for repair of tetralogy of Fallot? Circulation 2000; 102(19 Suppl 3): 123-29.

11. D'Anna C, Caputi A, Natali B, Leonardi B, Secinaro A, Rinelli G, et al. Improving the role of echocardiography in studying the right ventricle of repaired tetralogy of Fallot patients: comparison with cardiac magnetic resonance. Int J Cardiovasc Imaging 2018; 34(3): 399-06.

12. Egbe AC, Mittnacht AJ, Nguyen K, Joashi U. Risk factors for morbidity in infants undergoing tetralogy of fallot repair. Ann Pediatr Cardiol 2014; 7(1): 13-18.

13. Loomba RS, Buelow MW, Woods RK. Complete repair of tetralogy of fallot in the neonatal versus non-neonatal period: a meta-analysis. Paed Cardiol 2017; 38(5): 893-01.

14. Sandoval JP, Chaturvedi RR, Benson L, Morgan G, Van Arsdell G, Honjo O, et al. Right Ventricular Outflow Tract Stenting in Tetralogy of Fallot Infants With Risk Factors for Early Primary Repair. Cardiovasc Interv 2016; 9(12): e003979.

15. Paluszek C, Brenner P, Pichlmaier M, Haas NA, Dalla-Pozza R, Hagl C, et al. Risk Factors and Outcome of Post Fallot Repair Junctional Ectopic Tachycardia (JET). World J Paediatr Congenit Heart Surg 2019; 10(1): 50-57.

16. Kalfa DM, Serraf AE, Ly M, Le Bret E, Roussin R, Belli E. Tetralogy of Fallot with an abnormal coronary artery: surgical options and prognostic factors. Eur J Cardiothorac Surg 2012; 42(3): 34-39.

17. Doff B, Wise-Faberowski L, Asija R. Tetralogy of Fallot: Everything you wanted to know but were afraid to ask. Paediatr Anesth 2019; 29(5): 475-82.

18. Chaparro H, Abeldaño-Zuñiga RA. Factors associated with early extubation of patients after corrective tetralogy of Fallot. Enferm Intensiva 2019; 30(4): 154-62.

19. Guevara JH, Zorrilla-Vaca A, Silva-GordilloGC. The utility of preoperative level of erythrocytosis in the prediction of postoperative blood loss and 30-day mortality in patients with tetralogy of fallot, Ann Card Anaesth 2017; 20(2): 188-92.

20. Bhushan Sandeep Xin Huang, Fan Xu, Pengxiao Su, Ting Wang Xiaoke Sun. Etiology of right ventricular restrictive physiology early after repair of tetralogy of Fallot in pediatric patients. Cardio Thorac Surg 2019; 14(1): 84-86.

21. Egbe AC, Uppu SC, Mittnacht AJC, Joashi U, Ho D, Srivastava KNS. Primary tetralogy of Fallot repair: Predictors of intensive care unit morbidity Asian Cardiovascular \& Thoracic Annals 2014; 22(7): 794-99.

22. Abdelaziz O, Deraz S. Anticipation and management of junctional ectopic tachycardia in postoperative cardiac surgery: Single center experience with high incidence. Ann Pediatr Cardiol 2014; 7(1): 19-24.

23. Mimic B, Brown KL, Oswal N, Simmonds J, Hsia TY, Tsang VT, et al. Neither age at repair nor previous palliation affects outcome in tetralogy of Fallot repair. Eur J Cardiothorac Surg 2014; 45(1): 92-98.

24. d'Udekem Y, Ovaert C, Grandjean F, Gerin V, Cailteux M, Shango-Lody P, et al. Tetralogy of Fallot Transannular and Right Ventricular Patching Equally Affect Late Functional Status. Circulation 2018; 102(3): 116-22.

25. Luijten LW, van den Bosch E, Duppen N, Tanke R, RoosHesselink J, Nijveld A, et al. Long-term outcomes of transatrialtranspulmonary repair of tetralogy of Fallot. Eur J Cardiothorac Surg 2015; 47(1): 527-34. 